\title{
Retraction Note to: Experimental and Simulation Studies on Grain Growth in TiC- and WC-Based Cermets During Liquid Phase Sintering
}

\author{
Soon-Gi Shin ${ }^{1}$
}

Published online: 26 February 2018

(c) The Korean Institute of Metals and Materials 2018

\section{Retraction Note to: Metals and Materials International, Vol. 6, No. 3 (2000), pp. 195-201 https://doi.org/10.1007/BF03028212}

This article [1] has been retracted at the request of the Editor-in-Chief. Concerns were raised regarding substantial duplications with previous articles published in other journals in which S.-G. Shin is one of the co-authors. After a thorough analysis, we conclude that the concerns are valid. The article contains sections that substantially overlap with the following published articles [2, 3] (amongst others). S.-G. Shin has not responded to correspondence from the Editor about this retraction.
1. "Experimental and Simulation Studies on Grain Growth in TiC-and WC-Based Cermets During Liquid Phase Sintering" S.-G. Shin, Mat. Mater. Int., Vol. 6, Issue 3, pp. 195-201 (2000).

2. "Behaviors and Mechanism of Growth of Particles in Carbide Base Cermets" S.-G. Shin and S.-H. Lee, Bul. Kor. Inst. Met \& Mater Vol. 12, No. 5, pp. 564-573 (1999).

3. "Growth of Carbide Particles in $\mathrm{TiC}-\mathrm{Ni}$ and $\mathrm{TiC}-$ $\mathrm{Mo}_{2} \mathrm{C}-\mathrm{Ni}$ Cermets During Liquid Phase Sintering" $\mathrm{H}$. Matsubara, S.-G. Shin, and T. Sakuma, Materials Transactions, JIM, Vol. 32, No. 10, pp. 951-956 (1991).

The original article can be found online at https://doi.org/10.1007/ BF03028212.

Soon-Gi Shin

ssg@kangwon.ac.kr

1 R \& D Laboratory, Japan Fine Ceramics Center, 2-4-1

Mutsuno, Atsuta-ku, Nagoya 456-8587, Japan 